in vivo $35: 1033-1039(2021)$

doi:10.21873/invivo.12347

\title{
The Advantage of Pinpoint Camera System With Indocyanine Green for Sentinel Lymph Node Micrometastasis Detection in Low Risk Endometrial Cancer
}

\author{
ALEXANDROS LAZARIDIS ${ }^{1,2}$, STYLIANOS KOGEORGOS ${ }^{1}$, PANAGIOTIS BALINAKOS ${ }^{1}$, \\ KITTY PAVLAKIS ${ }^{3}$, THEOFANI GAVRESEA ${ }^{4}$ and GEORGE PISTOFIDIS ${ }^{1}$ \\ ${ }^{1}$ Department of Gynecologic Endoscopy, Lefkos Stavros Hospital, Athens, Greece; \\ ${ }^{2}$ Royal London Hospital, Barts Health NHS Trust, London, U.K.; \\ ${ }^{3}$ HBD Pathology Lab, Athens, Greece; \\ ${ }^{4}$ Biopath Innovations, Athens, Greece
}

\begin{abstract}
Background/Aim: This report outlines our experience in the management of 10 cases of low-risk endometrial cancer with Indocyanine Green for sentinel lymph node (SLN) mapping using the Pinpoint 30-degree $4 \mathrm{~K}$ S1 SPY real-time camera system (Stryker). This system offers simultaneous, real-time, high-definition white light and fluorescence imaging through a single laparoscope, without the need to change camera filters. Patients and Methods: In our retrospective case series we included all endometrioid endometrial cancers of grade Gl and pre-operative radiological staging FIGO $1 A$ reported on magnetic resonance imaging (MRI) that were treated laparoscopically from October 2019 to April 2020. Results: Bilateral sentinel lymph node excision was achieved in 9 out of 10 cases. In one patient, one sentinel lymph node featuring a micrometastasis of $<2 \mathrm{~mm}$ was identified. Conclusion: A specialist minimal access team can safely and reliably reproduce this technique for sentinel lymph node excision.
\end{abstract}

Endometrial cancer is the most common gynaecological malignancy and the incidence is rising (25\% increase over the last decade). This is grossly associated with an increase in the prevalence of risks factors, mainly obesity, nulliparity and an ageing population. Up to $34 \%$ of endometrial cancers

This article is freely accessible online.

Correspondence to: Alexandros Lazaridis, Department of Gynecologic Endoscopy, Lefkos Stavros Hospital, Athens, Greece \& Royal London Hospital, Barts Health NHS Trust, London, U.K. Tel: +30 2107233961, e-mail: alexanderlazaridis@hotmail.com

Key Words: Endometrial cancer, sentinel lymph node, laparoscopy, lymphadenectomy, indocyanine green, PinPoint camera system. are thought to be secondary to lifestyle and other external factors, and are therefore potentially preventable $(1,2)$.

Unfortunately, more women are dying of the disease despite improvements in overall survival $(2,3)$, due to the impact of increased incidence of cases between the ages of 60 and 79 years; while the incidence among younger patients has been relatively stable.

The low risk endometrioid (type 1) cancers are largely caused by excess oestrogen, unopposed progesterone and predominantly by obesity, which is the main driver for the increasing incidence globally (3). Fortunately, these lowgrade cancers are normally caught early resulting in better survival outcomes. On the other hand, the more aggressive (type 2) endometrial cancers (serous, clear cell), although less common than their endometrioid carcinoma (EEC) counterpart, account for a disproportionate number of endometrial cancer-related deaths (4).

Surgical management is still the mainstay for early-stage endometrial cancer, consisting of at least a hysterectomy and bilateral salpingo-oophorectomy. The laparoscopic route has become the standard approach in recent years, since a large number of trials have shown either equivalent or less intraoperative complications, less blood loss and reduced hospital stay (5). Moreover, it is oncologically safe to offer a laparoscopic approach for managing endometrial cancer $(6,7)$.

Even though a lot of progress has been witnessed over the last ten years on the treatment of early endometrioid endometrial cancer, there is still a debate on what the surgical procedure should involve, with some specialists advocating only on a conservative approach (hysterectomy and bilateral adnexectomy) and others a more radical approach comprising removal of pelvic lymph nodes. The origin of this debate stems from the usually low incidence of lymph node involvement during early stages of endometrial cancer and the debilitating morbidity of lymphadenectomy (8). 
Table I. Patients demographics and lymph node characteristics.

\begin{tabular}{|c|c|c|c|c|c|c|c|}
\hline $\begin{array}{l}\text { Age } \\
\text { (years) }\end{array}$ & BMI & $\begin{array}{l}\text { SLN Right } \\
(\mathrm{No})\end{array}$ & $\begin{array}{l}\text { SLN Left } \\
\text { (No) }\end{array}$ & $\begin{array}{c}\text { Anatomic location } \\
\text { of SLNs }\end{array}$ & $\begin{array}{c}\text { Grade (final } \\
\text { pathology) }\end{array}$ & $\begin{array}{r}\text { Stage (final } \\
\text { pathology) }\end{array}$ & $\begin{array}{l}\text { Duration of } \\
\text { the surgery }\end{array}$ \\
\hline 50 & 47 & 1 & 1 & External iliac & G1 & IA & 150 \\
\hline 44 & 31 & 3 & 1 & External iliac & G1 & IA & 120 \\
\hline 49 & 23 & 1 & 1 & External iliac & G1 & IA & 100 \\
\hline 52 & 30 & 1 & 1 & Obturator fossa & G1 & IIIC1 & 120 \\
\hline 66 & 30 & 1 & 1 & External iliac & G1 & IA & 110 \\
\hline 55 & 34 & 1 & 0 & External iliac & G1 & IA & 130 \\
\hline 53 & 32 & 1 & 1 & External iliac & G1 & IA & 140 \\
\hline 53 & 40 & 1 & 1 & External iliac & G1 & IA & 140 \\
\hline 53 & 33 & 2 & 1 & External iliac & G1 & IA & 120 \\
\hline 55 & 34 & 2 & 1 & External iliac & G1 & IA & 110 \\
\hline
\end{tabular}

BMI: Body mass index; SLN: sentinel lymph node: EBL: Estimate blood loss.

Therefore, the concept of sentinel lymph node (SLN) biopsy as opposed to a full node dissection has been proposed for staging endometrial cancers by the European Societies of Medical Oncology, Gynaecological Oncology, Radiology \& Oncology - (ESMO- ESGO- ESTRO) Consensus Conference on endometrial cancer (9), that supported the safety and efficacy of this technique. In any case, the SLN concept is not new and has been standard practice in cancers including melanoma, breast, and vulva, for many years.

Recent developments in imaging technology provide important real-time tools for intra-operative decision making. Indocyanine Green (ICG) fluorescence is one such system that involves injecting the fluorescent tracer ICG into the cervix, which can then be seen draining through the lymphatics using near infrared high intensity light cameras $(10,11)$.

\section{Patients and Methods}

In our retrospective case series, we describe the surgical steps of a safe laparoscopic treatment for low-risk endometrial cancer, where we proceeded with hysterectomy, bilateral salpingo-oophorectomy and SLN excision, using the cervical ICG fluorescence injection and the PinPoint fluorescence imaging technology from Stryker (Kalamazoo, MI, USA).

Even though the ICG fluorescent system is not a new revelation in clinical practice, yet the PinPoint technology was one of the first camera systems that offered simultaneous, real-time, high-definition white light and fluorescence imaging through a single laparoscope, without the need to change camera filters.

Practically this means that when the PinPoint fluorescent filter is activated, the surrounding tissues are seen with their natural colours, while the SLN stains fluorescent bright green. This enables surgeons to accurately visualize the pelvic anatomy and lymphatic tissue perfusion during minimally invasive procedures, and in our study, to highlight the SLNs while operating for endometrial cancer.

Inclusion criteria were: all grade G1 endometrioid endometrial cancers, with a pre-operative radiological staging FIGO 1A reported on MRI or pelvic ultrasound, which were treated laparoscopically from October 2019 to April 2020.

Overall, we identified and collected data from 10 cases after database interrogation. Median age of the study population was 53 years (range $=44-66$ years), BMI was $33\left(\right.$ range $=23-47 \mathrm{~kg} / \mathrm{m}^{2}$ ). All patients in our hospital sign a written consent form and concomitantly agree for their anonymised information to be published for teaching and research purposes (Table I).

Moreover, the hospitals advisory board granted approval for this publication and all patient identifiable information was handled in a manner that ensured anonymity.

Technique. The ICG injection protocol was applied following the Memorial Sloan Kettering SLN algorithm (12-14). The ICG concentration used was $1.25 \mathrm{mg} / \mathrm{ml}$. For each patient, a $5 \mathrm{mg}$ vial of ICG powder was diluted in $4 \mathrm{ml}$ of $\mathrm{NaCl} 0.9 \%$ solution. A total of 4 $\mathrm{ml}$ of ICG solution is then injected slowly into the cervix at a rate of 10 to $20 \mathrm{sec}$ per site at the 3 and 9 o'clock position ( $1 \mathrm{ml}$ deeply and $1 \mathrm{ml}$ superficially) after anaesthetic induction. None of our patients developed any reaction to the dye during or after the operation.

Following injection into the cervix, optimal detection of ICG will occur between 15 and $60 \mathrm{~min}$ (15). Successful mapping of a hemipelvis is defined by observing a channel leading from the cervix directly to at least one candidate lymph node. If the hemipelvis does not map, individualization of the management of the patient is necessary. Options include no further lymphadenectomy on that side (by practice or if the surgeon chooses to use the "Mayo criteria") or complete pelvic lymphadenectomy $(16,17)$.

In all cases, we carefully identified anatomical landmarks starting with the paracervical vessels and the external iliac vessels utilising the PinPoint optics system from Stryker. Then, with fine microdissection techniques using bipolar scissors (Bissinger Medizintechnik Teninger) and bipolar diathermy (Erbe Vio ${ }^{\circledR 3}$ Elektromedizin $\mathrm{GmbH}$ ), we opened the peritoneal folds superficially from the round ligament to the pelvic brim, identifying the ureters bilaterally. Fifteen minutes after the cervical injection, we alternate between the normal laparoscopic views and the fluorescence filter of the PinPoint optics system, which allows for real-time observation of the lymphatic channels on the pelvic sidewall. Deeper dissection continues with careful identification of the obturator nerve and 
A

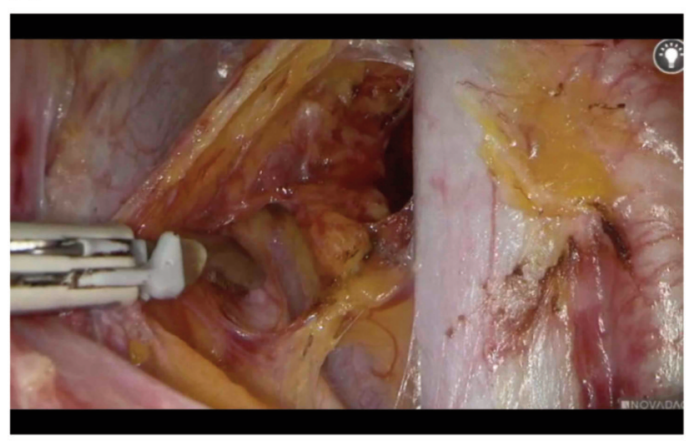

B

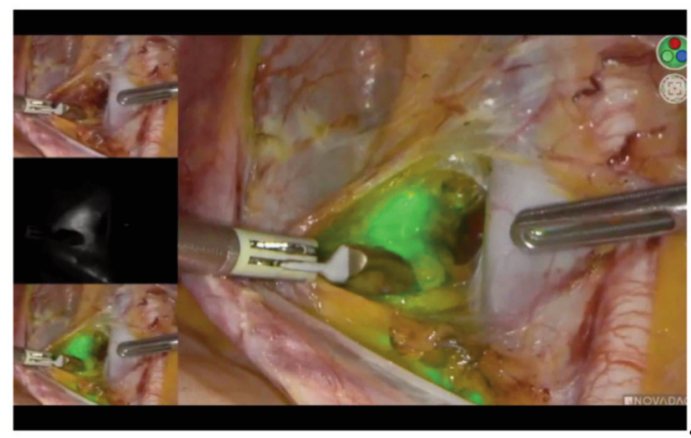

Figure 1. Right obturator fossa dissection. A: Pre indocyanine green (ICG) filter application. B: Post ICG filter application.

A

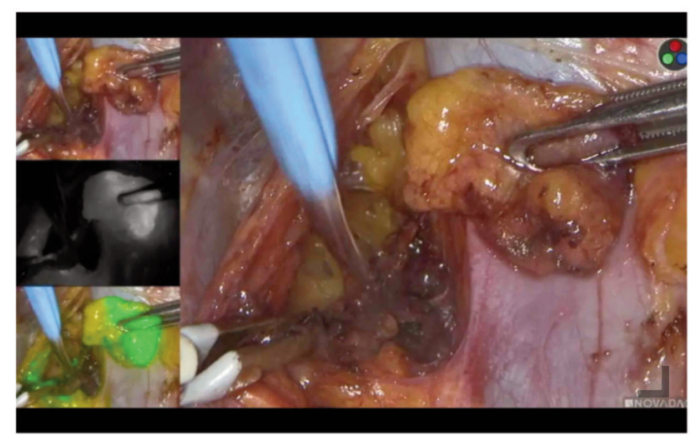

B

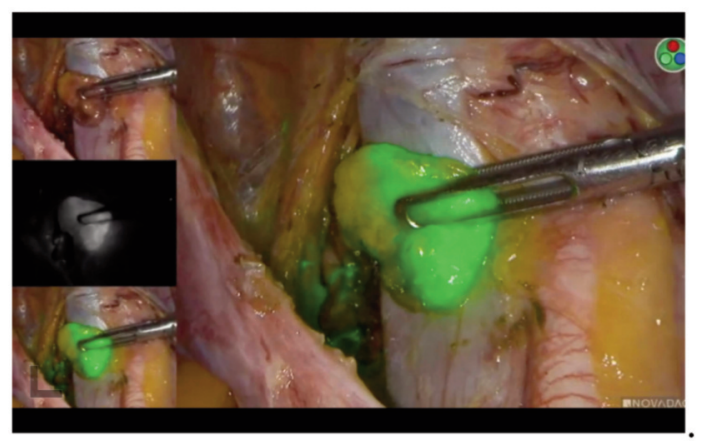

Figure 2. Right obturator SLN excision. A: Pre indocyanine green (ICG) filter application. B: Post ICG filter application.

collateral blood supplies arising from the internal and external iliac vessels. In doing so, we are carefully developing the anatomical spaces without damaging the lymphatic vessels, so that we limit the chances that the SLN remains unstained and therefore, surgically undetectable. We then proceed with the removal of the sentinel lymph node en-bloc, which is stained green from the ICG, giving the utmost attention to hemostasis and the sealing of all lymphatic ducts to prevent leakage post-operatively. Out of 10 cases, we performed bilateral SLN excision in 9 cases, and only on a single case was the SLN identified only on the right side (Table I).

\section{Results}

The median number of SLNs per hemi pelvises removed was 2 [standard deviation (SD)=1-3]. The Reiffenstuhl lymph node nomenclature (18) was utilized to define the SLNs anatomic location. SLNs were most frequently located in the external iliac vessels ( 21 nodes) on both sides. Two nodes were identified on the obturator fossa (Figure 1A, B).

All the procedures were successfully completed laparoscopically without conversion to open laparotomy. The technique for lymph node excision did not add significant intra-operative time, with a mean time of operation duration of $124 \mathrm{~min}$ (range $=100-150 \mathrm{~min}$ ). The blood loss in all cases was minimal (less than $50 \mathrm{ml}$ ) and no apparent intraoperative complications involving the lymphovascular spaces were identified (Table I).

All ten cases were carefully evaluated by our team consisting of minimal access and gynae-oncology specialists, as well as our specialist nurses, who followed the postoperative progress of our patients, with specific focus on post lymphadenectomy complications (lower limb lower swelling, paraesthesia, lymphocysts and lymphorrhea).

None of our patients reported any significant lower limb swelling necessitating the use of compression stocking to aid in the management of lymphoedema or any persistent vaginal discharge secondary to chyloperitoneum. In fact, the postoperative satisfaction visual analog scores of the group that underwent SLN excision were similar to a control group that underwent simple hysterectomy and bilateral salpingooophorectomy for a benign pathology during the same time from our team, with no significant statistical differences on the bowel, bladder and lower limb functions. 


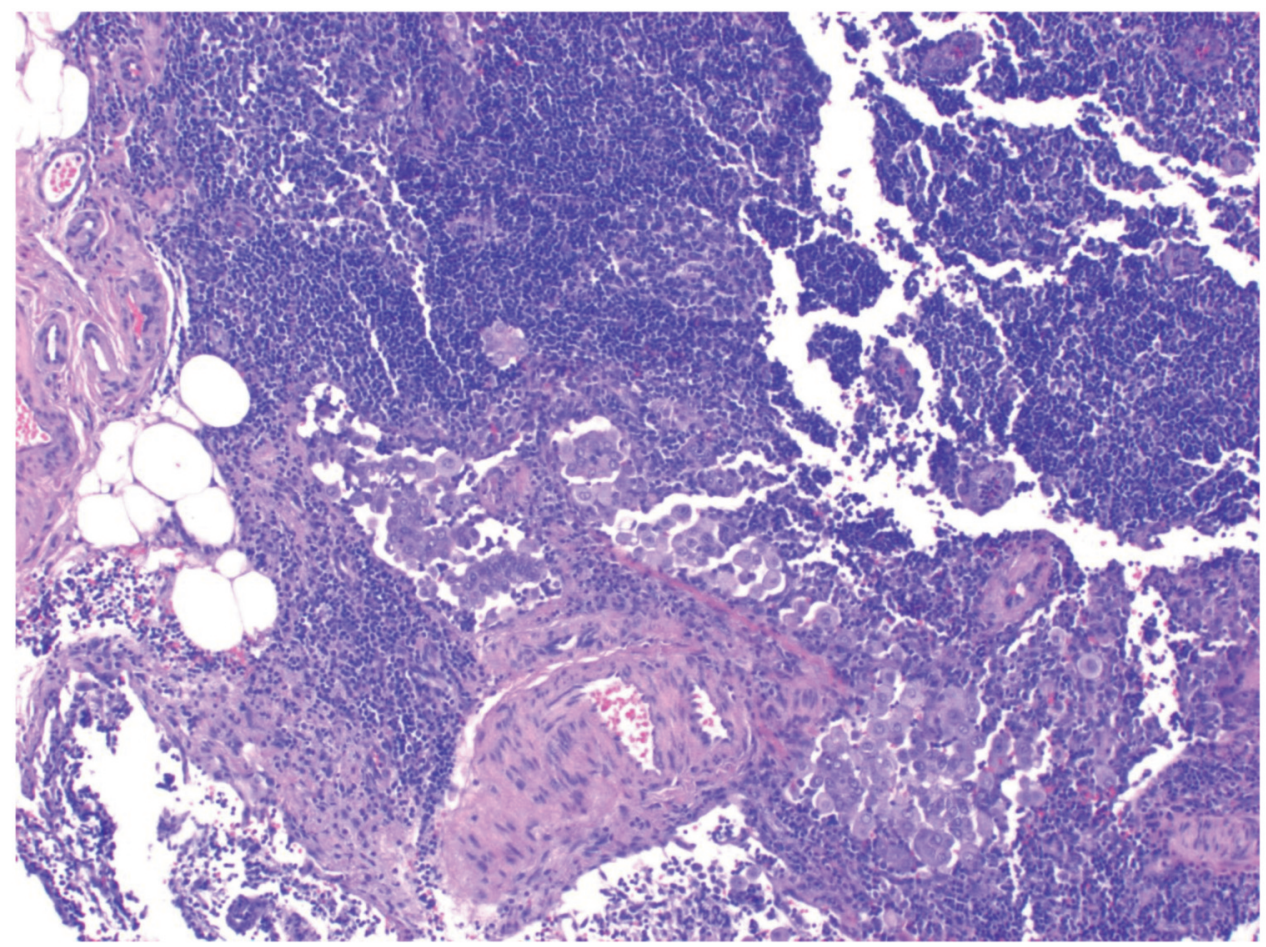

Figure 3. $H \& E$ staining of a micrometastasis $(<2 \mathrm{~mm})$ in a sentinel lymph node $(\times 100)$.

Sentinel lymph node processing. Each SLN was sectioned perpendicular to the long axis at $3 \mathrm{~mm}$ intervals. The sections were then entirely submitted for routine processing and $\mathrm{H} \& \mathrm{E}$ staining. When the initial H\&E stains failed to reveal a metastasis, further evaluation was considered. Specifically, from each paraffin block, 4 levels at $200 \mu \mathrm{m}$ apart were further processed with $\mathrm{H} \& \mathrm{E}$ and immunohistochemical staining with Keratin AE1/AE3 at each level (9).

Only in one patient, one sentinel lymph node featuring a micrometastasis of $<2 \mathrm{~mm}$ was identified (Figures 2, 3 and 4). This detection resulted in an upstaging of the carcinoma and further treatment of the patient with adjuvant chemo- and radio-therapy (14) was performed. No macrometastases were identified.

\section{Discussion}

This report outlines our experience in the management of lowrisk endometrial cancers with ICG fluorescence for SLN mapping using the Pinpoint 30-degree 4K S1 SPY real-time camera system (PinPoint Endoscopic Fluorescence Imaging System, Stryker), which allows surgeons to have a better intraoperative visualization of the lymphatic channels with the aid of near infrared real-time fluorescence. Due to the lack of convincing evidence, there is no international consensus in the staging approach regarding low-risk endometrial cancers.
In 2009, the ASTEC trial (19) did not identify any therapeutic benefits for routine lymphadenectomy in earlystage endometrial cancer. Consequently, even though there are a few criticisms on the study design (i.e. quality control of lymphadenectomy) (20), several centres now do not routinely perform lymphadenectomy for early stage endometrial cancer.

On the other hand, another retrospective study, 'SEPAL' (21), a year later, as well as previous case-control studies $(22,23)$, have demonstrated significantly longer survival in patients undergoing systematic pelvic and para-aortic lymphadenectomy. It is unclear whether this was a direct effect of dissection or a consequence of increased identification of cases requiring additional treatment.

Given the above two opposite poles regarding lymphadenectomy for early stage endometrial cancer and acknowledging that metastatic spread of disease to the lymph nodes is the most important prognostic factor for women with endometrial cancer (24), the use of SLN excision may represent a silver lining in the management of such cases (25). Recent prospective and retrospective evidence supports the use of SLN since there is increased detection of lymph node metastasis with a low false-negative rate, when compared with systematic lymphadenectomy $(8,26)$.

Consequently, both the National Comprehensive Cancer Network NCCN and the Society of Gynaecological Oncology 


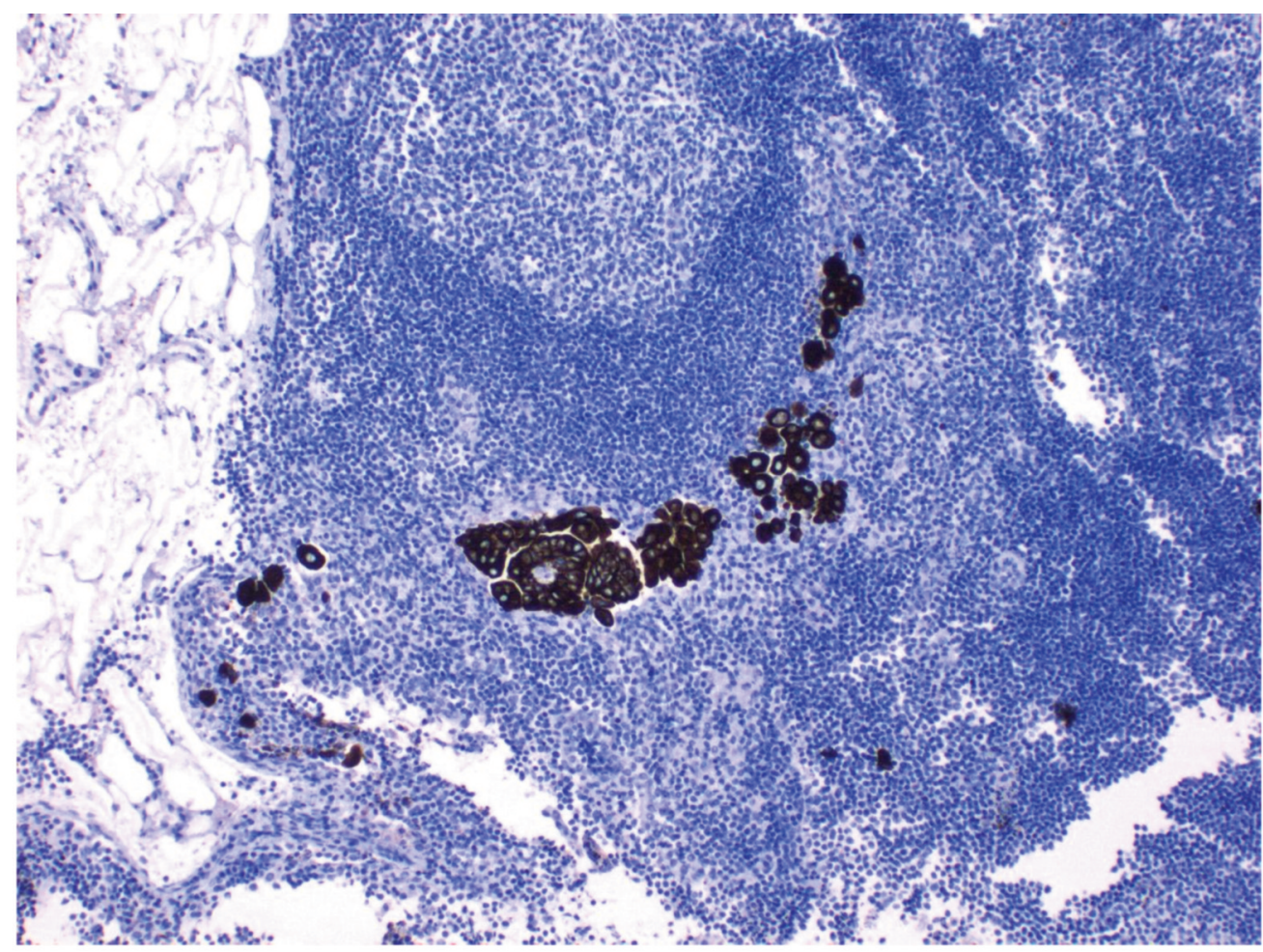

Figure 4. The same lymph node shown in Figure 3, stained immunohistochemically with Ker AE1/AE3 (x100).

SGO (27) support the role of SLN excision in the management of women with endometrial cancer, even though the absence of randomized studies comparing sentinel lymphadenectomy with alternative strategies in the evaluation of pelvic lymph nodes has been noted (14). Nevertheless, the importance of low volume nodal metastases, which is increasingly detected by enhanced pathological ultrastaging of SLN, has been recently highlighted $(28,29)$.

In recent years, SLN mapping has received increasing attention in cervical and endometrial cancers, with the aim of minimizing treatment-related morbidity while maintaining the benefit of surgical staging (30). There is growing evidence nowadays that ICG with the use of near infra-red laparoscopic optics provides a safe, reliable and feasible alternative to the traditional methods for SN mapping, which include the methylene blue dye and radiolabelled tracers such as Tc-99m albumin nanocolloid that allows preoperative imaging with planar scintigraphy and Single Photon Emission Tomography/Computed Tomography (SPET/CT) (31). As a technique, the ICG fluorescence offers the benefits of time efficiency and superior lymph node detection rates compared to the alternative methods mentioned above.

In our preliminary experience, SLN detection with ICG fluorescence demonstrated a high detection rate (100\%) with bilateral mapping of $90 \%$, which is in concordance with other published studies (32-34). Unilateral SLN mapping was observed in only one patient, which represents a $10 \%$, due to our small number of cases included. Moreover, this technique compared to the traditional techniques described above is less expensive and time consuming, since it bypasses the need for nuclear medicine technicians and expensive equipment. Furthermore, in the hands of an expert minimal access team, it is a very safe, reliable and easily reproducible technique for sentinel lymph node evaluation for the management of early stage endometrioid endometrial cancer. In our series we were able to demonstrate adequate staging without significant extension of operative time or peri-operative complications related to our technique.

Our retrospective study is limited by the small number of patients included. Nevertheless, even with this small group of patients, we were able to detect micrometastasis, which was of significant importance for further management.

\section{Conclusion}

Unfortunately, our generation will witness a gradual rise in low-risk endometrial cancers which, in most cases, will present in early stages, where a complete surgical treatment and SLN excision will confer maximum benefits to patients' survival and quality of life. 
We advocate that the intra-operative use of ICG fluorescence is a necessary weapon in our arsenal for the proper management of such cases. Therefore, future surgeons should participate and train with expert minimal access teams in order to familiarize with the technology and adopt such advanced techniques in their surgical repertoire.

\section{Conflicts of Interest}

The Authors have no conflicts of interest to declare regarding this study.

\section{Authors' Contributions}

Conception \& presentation of the idea: GP, SK; Data collection: SK, PB; Data analysis: SK, AL; Perfomed the literature search: AL, SK; Original manuscript writing: AL; Primary manuscript revisions: AL, SK, GP, KP; Secondary manuscript reviews: PB, TG; Video and images compilation: AL, SK, KP.

\section{References}

1 Parkin DM, Boyd L and Walker LC: The fraction of cancer attributable to lifestyle and environmental factors in the UK in 2010. Br J Cancer 105: S77-81, 2011. PMID: 22158327. DOI: 10.1038/bjc.2011.489

2 Ferlay J, Shin HR, Bray F, Forman D, Mathers C and Parkin DM: Estimates of worldwide burden of cancer in 2008: GLOBOCAN 2008. Int J Clin 127(12): 2893-2917, 2010. PMID: 21351269. DOI: $10.1002 /$ ijc. 25516

3 Bray F, Ferlay J, Soerjomataram I, Siegel RL, Torre LA and Jemal A: Global cancer statistics 2018: GLOBOCAN estimates of incidence and mortality worldwide for 36 cancers in 185 countries. CA Cancer J Clin 68: 394-424, 2018. PMID: 30207593. DOI: $10.3322 /$ caac. 21492

4 Boruta DM 2nd, Gehrig PA, Fader AN and Olawaiye AB: Management of women with uterine papillary serous cancer: A Society of Gynecologic Oncology (SGO) review. Gynecol Oncol 115(1): 142-153, 2019. PMID: 19592079. DOI: 10.1016/ j.ygyno.2009.06.011

5 Walker JL: Laparoscopy compared with laparotomy for comprehensive surgical staging of uterine cancer: Gynecologic Oncology Group Study LAP2. J Clin Oncol 27: 5331-5336, 2009. PMID: 19805679. DOI: 10.1200/JCO.2009.22.3248

6 Graves N, Janda M, Merollini K, Gebski V, Obermair A and LACE Trial Committee: The cost-effectiveness of total laparoscopic hysterectomy compared to total abdominal hysterectomy for the treatment of early-stage endometrial cancer. BMJ Open 3(4): e001884, 2013. PMID: 23604345. DOI: 10.1136/bmjopen-2012-001884

7 Janda M, Gebski V, Brand A, Hogg R, Jobling TW, Land R, Manolitsas T, McCartney A, Nascimento M, Neesham D, Nicklin JL, Oehler MK, Otton G, Perrin L, Salfinger S, Hammond I, Leung Y, Walsh T, Sykes P, Ngan H, Garrett A, Laney M, Ng TY, Tam K, Chan K, Wrede CD, Pather S, Simcock B, Farrell R and Obermair A: Quality of life after total laparoscopic hysterectomy versus total abdominal hysterectomy for stage I endometrial cancer (LACE): a randomised trial. Lancet Oncol 11: 772-780, 210. PMID: 20638899. DOI: 10.1016/S1470-2045(10)70145-5
8 Colombo N, Creutzberg C, Amant F, Bosse T, González-Martín A, Ledermann J, Marth C, Nout R, Querleu D, Mirza MR and Sessa C: ESMO-ESGO-ESTRO Endometrial Consensus Conference Working Group. Ann Oncol 27(1): 16-41, 2016. PMID: 26634381. DOI: 10.1093/annonc/mdv484

9 Ballester M, Dubernard G, Lécuru F, Heitz D, Mathevet P, Marret H, Querleu D, Golfier F, Leblanc E, Rouzier R and Daraï E: Detection rate and diagnostic accuracy of sentinel-node biopsy in early-stage endometrial cancer: a prospective multicentre study (SENTI-ENDO). Lancet Oncol 2(5): 469-476, 2011. PMID: 21489874. DOI: 10.1016/S1470-2045(11)70070-5

10 Cormier B, Rozenholc AT, Gotlieb W, Plante M, Giede C and Communities of Practice (CoP) Group of Society of Gynecologic Oncology of Canada (GOC): Sentinel lymph node procedure in endometrial cancer: A systematic review and proposal for standardization of future research. Gynecol Oncol 138(2): 478-485, 2015. PMID: 26047592. DOI: 10.1016/ j.ygyno.2015.05.039

11 Zahl Eriksson AG, Ducie J, Ali N, McGree ME, Weaver AL, Bogani G, Cliby WA, Dowdy SC, Bakkum-Gamez JN, AbuRustum NR, Mariani A and Leitao MM Jr: Comparison of a sentinel lymph node and a selective lymphadenectomy algorithm in patients with endometrioid endometrial carcinoma and limited myometrial invasion. Gynecol Oncol 140(3): 394-399, 2016. PMID: 26747778. DOI: 10.1016/j.ygyno.2015.12.028.

12 Barlin JN, Khoury-Collado F, Kim CH, Leitao MM Jr, Chi DS, Sonoda Y, Alektiar K, DeLair DF, Barakat RR and Abu-Rustum NR: The importance of applying a sentinel lymph node mapping algorithm in endometrial cancer staging: beyond removal of blue nodes. Gynecol Oncol 125(3): 531-535, 2012. PMID: 22366409. DOI: 10.1016/j.ygyno.2012.02.021

13 Khoury-Collado F, St Clair C and Abu-Rustum NR: Sentinel lymph node mapping in endometrial cancer: an update. Oncologist 21(4): 461-466, 2016. PMID: 26961924. DOI: 10.1634/theoncologist.2015-0473

14 Uterine Neoplasms, Version 2. 2020. NCCN Clinical Practice Guidelines in Oncology.

15 Rossi EC, Ivanova A and Boggess JF: Robotically assisted fluorescence-guided lymph node mapping with ICG for gynecologic malignancies: a feasibility study. Gynecol Oncol 124(1): 78-82, 2012. PMID: 21996262. DOI: 10.1016/j.ygyno. 2011.09.025

16 Convery PA, Cantrell LA, Di Santo N, Broadwater G, Modesitt SC, Secord AA and Havrilesky LJ: Retrospective review of an intraoperative algorithm to predict lymph node metastasis in low-grade endometrial adenocarcinoma. Gynecol Oncol 123(1): 65-70, 2011. PMID: 21742369. DOI: 10.1016/j.ygyno.2011. 06.025

17 Zhang M, Isaksson Vogel R and Rivard C: Evaluating the use of a modified Mayo criteria for early stage endometrial cancer surgical staging. Gynecol Oncol 147: 230, 2017. DOI: 10.1016/j.ygyno.2017.07.104

18 Reiffenstuhl G: Contribution on the nomenclature of the pelvic lymph nodes [Article in German]. Wien Klin Wochenschr 68(12): 247-248, 1956. PMID: 13338265.

19 ASTEC study group, Kitchener H, Swart AM, Qian Q, Amos C and Parmar MK: Efficacy of systematic pelvic lymphadenectomy in endometrial cancer (MRC ASTEC trial): A randomised study. Lancet 373(9658): 125-136, 2009. PMID: 19070889. DOI: 10.1016/S0140-6736(08)61766-3 
20 Naumann RW: The role of lymphadenectomy in endometrial cancer: was the ASTEC trial doomed by design and are we destined to repeat that mistake? Gynecol Oncol 126(1): 5-11, 2012. PMID: 22555109. DOI: 10.1016/j.ygyno.2012.04.040

21 Todo Y, Kato H, Kaneuchi M, Watari H, Takeda M and Sakuragi $\mathrm{N}$ : Survival effect of para-aortic lymphadenectomy in endometrial cancer (SEPAL study): a retrospective cohort analysis. Lancet 375(9721): 1165-1172, 2010. PMID: 20188410. DOI: 10.1016/S0140-6736(09)62002-X

22 Chan JK, Cheung MK, Huh WK, Osann K, Husain A, Teng NN and Kapp DS: Therapeutic role of lymph node resection in endometrioid corpus cancer: a study of 12,333 patients. Cancer 107(8): 1823-1830, 2006. PMID: 16977653. DOI: 10.1002/ cncr.22185

23 Cragun JM, Havrilesky LJ, Calingaert B, Synan I, Secord AA, Soper JT, Clarke-Pearson DL and Berchuck A: Retrospective analysis of selective lymphadenectomy in apparent early-stage endometrial cancer. J Clin Oncol 23(16): 3668-3675, 2005. PMID: 15738538. DOI: 10.1200/JCO.2005.04.144

24 Gómez-Hidalgo NR, Ramirez PT, Ngo B, Pérez-Hoyos S, Coreas N, Sanchez-Iglesias JL, Cabrera S, Franco S, Benavente $\mathrm{AP}$ and Gil-Moreno A: Oncologic impact of micrometastases or isolated tumor cells in sentinel lymph nodes of patients with endometrial cancer: a meta-analysis. Clin Transl Oncol 22(8): 1272-1279, 2020. PMID: 31863354. DOI: 10.1007/s12094-01902249-x

25 Imboden S, Mereu L, Siegenthaler F, Pellegrini A, Papadia A, Tateo S and Mueller MD: Oncological safety and perioperative morbidity in low-risk endometrial cancer with sentinel lymphnode dissection. Eur J Surg Oncol 45(9): 1638-1643, 2019. PMID: 31229377. DOI: 10.1016/j.ejso.2019.05.026

26. Rossi EC, Kowalski LD, Scalici J, Cantrell L, Schuler K, Hanna RK, Method M, Ade M, Ivanova A and Boggess JF: A comparison of sentinel lymph node biopsy to lymphadenectomy for endometrial cancer staging (FIRES trial): a multicentre, prospective, cohort study. Lancet Oncol 18(3): 384-392, 2017. PMID: 28159465. DOI: 10.1016/S1470-2045(17)30068-2

27 Holloway RW, Abu-Rustum NR, Backes FJ, Boggess JF, Gotlieb WH, Jeffrey Lowery W, Rossi EC, Tanner EJ and Wolsky RJ: Sentinel lymph node mapping and staging in endometrial cancer: A Society of Gynecologic Oncology literature review with consensus recommendations. Gynecol Oncol 146(2): 405-415, 2017. PMID: 28566221. DOI: 10.1016/j.ygyno.2017.05.027

28 Leitao MM Jr, Khoury-Collado F, Gardner G, Sonoda Y, Brown CL, Alektiar KM, Hensley ML, Soslow RA, Barakat RR and Abu-Rustum NR: Impact of incorporating an algorithm that utilizes sentinel lymph node mapping during minimally invasive procedures on the detection of stage IIIC endometrial cancer. Gynecol Oncol 129(1): 38-41, 2013. PMID: 23321065. DOI: 10.1016/j.ygyno.2013.01.002
29 Cibula D, Abu-Rustum NR, Dusek L, Zikán M, Zaal A, Sevcik L, Kenter GG, Querleu D, Jach R, Bats AS, Dyduch G, Graf P, Klat J, Lacheta J, Meijer CJ, Mery E, Verheijen R and Zweemer RP: Prognostic significance of low volume sentinel lymph node disease in early-stage cervical cancer. Gynecol Oncol 124(3): 496-501, 2012. PMID: 22120175. DOI: 10.1016/j.ygyno. 2011.11.037

30 Bellaminutti S, Bonollo M, Gasparri ML, Clivio L, Migliora P, Mazzucchelli L and Papadia A: Sentinel lymph node intraoperative analysis in endometrial cancer. J Cancer Res Clin Oncol 146(12): 3199-3205, 2020. PMID: 32815026. DOI: 10.1007/s00432-020-03356-x

31 Buda A, Crivellaro C, Elisei F, Di Martino G, Guerra L, De Ponti E, Cuzzocrea M, Giuliani D, Sina F, Magni S, Landoni C and Milani R: Impact of indocyanine green for sentinel lymph node mapping in early stage endometrial and cervical cancer: Comparison with conventional radiotracer $(99 \mathrm{~m}) \mathrm{Tc}$ and/or blue dye. Ann Surg Oncol 23(7): 2183-2191, 2016. PMID: 26714944. DOI: $10.1245 / \mathrm{s} 10434-015-5022-1$

32 Jewell EL, Huang JJ, Abu-Rustum NR, Gardner GJ, Brown CL, Sonoda Y, Barakat RR, Levine DA and Leitao MM Jr: Detection of sentinel lymph nodes in minimally invasive surgery using indocyanine green and near-infrared fluorescence imaging for uterine and cervical malignancies. Gynecol Oncol 133(2): 274277, 2014. PMID: 24582865. DOI: 10.1016/j.ygyno 2014.02.028

33 Plante M, Touhami O, Trinh XB, Renaud MC, Sebastianelli A, Grondin K and Gregoire J: Sentinel node mapping with indocyanine green and endoscopic near-infrared fluorescence imaging in endometrial cancer. A pilot study and review of the literature. Gynecol Oncol 137(3): 443-447, 2015. PMID: 25771495. DOI: 10.1016/j.ygyno.2015.03.004

34 How J, Gotlieb WH, Press JZ, Abitbol J, Pelmus M, Ferenczy A, Probst S, Gotlieb R, Brin S and Lau S: Comparing indocyanine green, technetium, and blue dye for sentinel lymph node mapping in endometrial cancer. Gynecol Oncol 137(3): 436-442, 2015. PMID: 25870917. DOI: 10.1016/j.ygyno. 2015.04.004

Received September 29, 2020

Revised December 9, 2020

Accepted December 15, 2020 